\title{
Integration of metabolomics, transcriptomics, and microRNA expression profiling reveals a miR-143-HK2-glucose network underlying zinc-deficiency-associated esophageal neoplasia
}

\author{
Louise Y. Fong ${ }^{1,2,3}$, Ruiyan Jing ${ }^{1}$, Karl J. Smalley ${ }^{2}$, Cristian Taccioli ${ }^{4}$, Johannes \\ Fahrmann ${ }^{5}$, Dinesh K. Barupal ${ }^{\text {, }}$, Hansjuerg Alder ${ }^{7}$, John L. Farber ${ }^{1}$, Oliver Fiehnn ${ }^{5,6}$ \\ and Carlo M. Croce ${ }^{7}$ \\ ${ }^{1}$ Department of Pathology, Anatomy \& Cell Biology, Thomas Jefferson University, Philadelphia, PA, USA \\ ${ }^{2}$ Sidney Kimmel Cancer Center, Thomas Jefferson University, Philadelphia, PA, USA \\ ${ }^{3}$ Center for Molecular Carcinogenesis, Thomas Jefferson University, Philadelphia, PA, USA \\ ${ }^{4}$ Animal Medicine, Production and Health Department, University of Padua, Padua, Italy \\ ${ }^{5}$ University of California, Davis, West Coast Metabolomics Center, Davis, CA, USA \\ ${ }^{6}$ Department of Biochemistry, Faculty of Sciences, King Abdulaziz University, Jeddah, Saudi Arabia \\ 7 Department of Molecular Virology, Immunology, and Medical Genetics, Comprehensive Cancer Center, The Ohio State \\ University, Columbus, $\mathrm{OH}$, USA \\ Correspondence to: Lovise Y. Fong, email: lovise.fong@jefferson.edu
}

Carlo M. Croce, email: carlo.croce@osumc.edu

Keywords: metabolomic profiling, transcriptomics and microRNA profiling integration, esophageal neoplasia, dietary zinc-deficiency, miR-143 - Hk2 - glucose signaling

$\begin{array}{lll}\text { Received: April 27, } 2017 \quad \text { Accepted: May 29, } 2017 & \text { Published: June 09, } 2017\end{array}$

Copyright: Fong et al. This is an open-access article distributed under the terms of the Creative Commons Attribution License 3.0 (CC BY

3.0), which permits unrestricted use, distribution, and reproduction in any medium, provided the original author and source are credited.

\section{ABSTRACT}

Esophageal squamous cell carcinoma (ESCC) in humans is a deadly disease associated with dietary zinc ( $\mathrm{Zn}$ )-deficiency. In the rat esophagus, $\mathrm{Zn}$-deficiency induces cell proliferation, alters mRNA and microRNA gene expression, and promotes ESCC. We investigated whether Zn-deficiency alters cell metabolism by evaluating metabolomic profiles of esophageal epithelia from $\mathrm{Zn}$-deficient and replenished rats vs sufficient rats, using untargeted gas chromatography time-of-flight mass spectrometry ( $n=8 /$ group). The $\mathrm{Zn}$-deficient proliferative esophagus exhibits a distinct metabolic profile with glucose down 153-fold and lactic acid up 1.7-fold ( $P$ $<0.0001$ ), indicating aerobic glycolysis (the "Warburg effect"), a hallmark of cancer cells. Zn-replenishment rapidly increases glucose content, restores deregulated metabolites to control levels, and reverses the hyperplastic phenotype. Integration of metabolomics and our reported transcriptomic data for this tissue unveils a link between glucose down-regulation and overexpression of $\mathrm{HK2}$, an enzyme that catalyzes the first step of glycolysis and is overexpressed in cancer cells. Searching our published microRNA profile, we find that the tumor-suppressor miR-143, a negative regulator of $\mathrm{HK2}$, is down-regulated in Zn-deficient esophagus. Using in situ hybridization and immunohistochemical analysis, the inverse correlation between miR-143 down-regulation and HK2 overexpression is documented in hyperplastic Zndeficient esophagus, archived ESCC-bearing Zn-deficient esophagus, and human ESCC tissues. Thus, to sustain uncontrolled cell proliferation, $\mathrm{Zn}$-deficiency reprograms glucose metabolism by modulating expression of miR-143 and its target HK2. Our work provides new insight into critical roles of $\mathrm{Zn}$ in ESCC development and prevention. 


\section{INTRODUCTION}

Although cancer mortality rates have declined worldwide since the mid 1980s, esophageal squamous cell carcinoma (ESCC), the predominant esophageal cancer subtype, has a 5-year survival of only 10\% [1]. Due to lack of early symptoms, ESCC is typically diagnosed at an advanced stage that defies treatment by surgery combined with radio/chemotherapy. Thus, clarification of the mechanisms underlying the pathogenesis of ESCC and development of new prevention and therapeutic strategies are critically needed.

Zinc (Zn)-deficiency (ZD) is recognized as a major worldwide public health problem [2-6], affecting $\sim 31 \%$ of the global population with higher rates in developing countries [5]. Although severe ZD is uncommon, mildto-moderate $\mathrm{ZD}$ is prevalent throughout the world [7]. Epidemiologic and clinical studies have implicated dietary ZD in the etiology of ESCC [8-10]. Specifically, Abnet et al. [11] demonstrated that tissue $\mathrm{Zn}$ concentration is inversely associated with the subsequent risk of developing ESCC. Because $\mathrm{Zn}$ is required for the activity of hundreds of enzymes, for proper immune function, and for the conformation of $>2000$ transcription factors that control cell proliferation, apoptosis, and signaling pathways [12, 13], ZD predisposes to disease by adversely affecting many processes.

Cell proliferation is a hall mark of cancer [14]. Previously, we showed that rats on a ZD diet for $\sim 6$ weeks develop a hyperplastic esophagus with sustained, uncontrolled cell proliferation [15]. In transcriptome analyses using DNA microarrays, the ZD esophagus showed a distinct gene expression signature with the proinflammation mediators S100a8/a9 as the top upregulated genes [16]. Zn-replenishment (ZR) rapidly restored to control levels the expression of S100A8/A9 and other genes and reversed the hyperplastic phenotype [16]. In addition, prolonged ZD (21 weeks) leads to an expanded cancer-associated inflammatory program that when combined with non-carcinogenic low doses of the environmental carcinogen $N$-nitrosomethylbenzylamine (NMBA), elicited a 67\% incidence of ESCC [17]. Among the up-regulated genes were genes known as hallmarks of cancer-related inflammation (chemokines, cytokines, prostaglandins) implicated in the development of human cancers, including ESCC [18, 19]. Again, ZR reversed this inflammatory gene signature and prevented cancer formation $[17,20]$. Thus, our ZD rat esophageal cancer model reproduces the path to human ESCC and provides an opportunity to understand the molecular basis of ESCC associated with ZD.

MicroRNAs (miRNA) are short non-coding RNAs that regulate gene expression by translational inhibition and mRNA degradation. Individual miRNAs can inhibit multiple target genes or entire signaling pathways, including cell proliferation, differentiation, and apoptosis.
miRNA expression levels are altered in all human cancers studied, including ESCC [21], can act as oncogenes or tumor suppressors $[22,23]$ and have emerged as therapeutic targets for cancer [24]. Using the NanoString microRNA expression profiling platform, we showed that ZD promotes ESCC by inducing an oncogenic miRNA signature that resembles the human ESCC miRNAome [25] with up-regulation of oncogenic miR-31, -223, and -21 [26-28]. Additionally, ESCC development and the underlying miRNA dysregulation are dependent on the extent of dietary deficiency of $\mathrm{Zn}$ [28].

In the early 1920s, Warburg discovered that unlike normal tissues, tumor cells convert glucose to lactate even under aerobic condition, establishing that cancer cells exhibit altered cellular metabolism fundamental to carcinogenesis $[29,30]$. In the ensuing years, this phenomenon of aerobic glycolysis or Warburg effect has been documented in a variety of human cancers, including ESCC [31], most readily by assessing glucose uptake using positron emission tomography (PET) with a radiolabeled analog of glucose $\left({ }^{118} \mathrm{~F}\right.$-fuorodeoxyglucose, FDG) as reporter. Altered metabolism is now considered a hallmark of cancer [14], and deregulated uptake of glucose is a common feature of cancer-associated metabolic changes [32].

Given that altered metabolism results from active reprogramming by altered oncogenes and tumor suppressors [33], these metabolite changes are downstream and complementary to changes in genes and proteins and are key players in biological networks. Additionally, miRNAs have emerged as key regulators of cellular metabolism in normal and pathological conditions [34]. For example, miR-122 and its host gene regulate cholesterol and lipid metabolism in liver [35]; miR-143 and its target gene, HK2, regulates aerobic glycolysis in tumor cells [36-39].

We hypothesized that in addition to inducing a hyperplastic esophageal phenotype along with oncogenic alterations in mRNA and miRNA gene expression, dietary ZD also causes altered cellular metabolism during early esophageal carcinogenesis. To investigate this, we performed untargeted metabolomic profiling by gas chromatography time-of-flight mass spectrometry (GCTOF MS) to evaluate metabolite changes in esophageal mucosa obtained from ZD rats vs ZS rats [16]. GC-TOF MS based metabolic profiling has been used for studying primary metabolism (sugars, lipids, \& small peptides) in the characterization of human cancers such as ovarian carcinoma [40, 41] and lung adenocarcinoma [42-44]. To gain insights into the molecular basis of alterations in biochemical pathways, we integrated metabolomics of ZD rat esophagus with our reported transcriptome dataset for this tissue from a study of identical design [16]. We also investigated whether a miRNA-mRNA-metabolite network can be established in early ZD-associated esophageal tumor development by searching our reported miRNA profile data [28]. 


\section{RESULTS}

Esophageal mucosa samples for GC-TOF MSbased analysis

Esophageal mucosa samples were obtained from Zn-modulated rats after a 6-week dietary regimen as described before [16]. Consistent with previous studies $[15,16,20]$, the $\mathrm{Zn}$ status marker, testis $\mathrm{Zn}$ content $(\mu \mathrm{g} / \mathrm{g}$ dry weight, mean $\pm \mathrm{SD}$ ), was significantly lower in $\mathrm{ZD}$ than control ZS rats $(105 \pm 18 v s 131 \pm 6.8, P<0.01, n$ $=8$ rats $/$ group). Also, the $\mathrm{ZD}$ esophagus was hyperplastic with a high rate of cell proliferation, as compared with ZS esophagus that is typically 2 to 3 cells thick. Seventy-two hours after replenishing $\mathrm{Zn}$, testis zinc content in ZR rats was $139 \pm 11 \mu \mathrm{g} / \mathrm{g}$ dry weight, a result comparable to ZS rats. At the same time, ZR esophagus reverted to a near normal esophageal phenotype, consistent with previous studies [16, 20].
Metabolic profile of hyperplastic ZD esophagus

Metabolomic analysis by GC-TOF MS in esophageal mucosa from ZD and ZS rats ( $n=8$ per group) yielded a total of 353 compounds, of these 155 were structurally known metabolites and 198 were unknown compounds. Using a cutoff point of $P$ value $<0.05$ and $\geq 1.3$-fold difference, the proliferative $\mathrm{ZD}$ esophagus exhibited a distinct metabolic signature as compared with its non-proliferative ZS counterpart. A total of 71 known metabolites were significantly altered, with 27 metabolites down-regulated and 44 up-regulated (Table 1). To display the biochemical differences between hyperplastic ZD and control ZS esophagus, a metabolomic network [45] was calculated among the structurally identified metabolites using the Kyoto encyclopedia of genes and genomes (KEGG ) databases [46] and PubChem CIDs identifiers [47] (Figure 1).

Of the 27 metabolites that were significantly downregulated in the hyperplastic $\mathrm{ZD}$ esophagus, sixteen

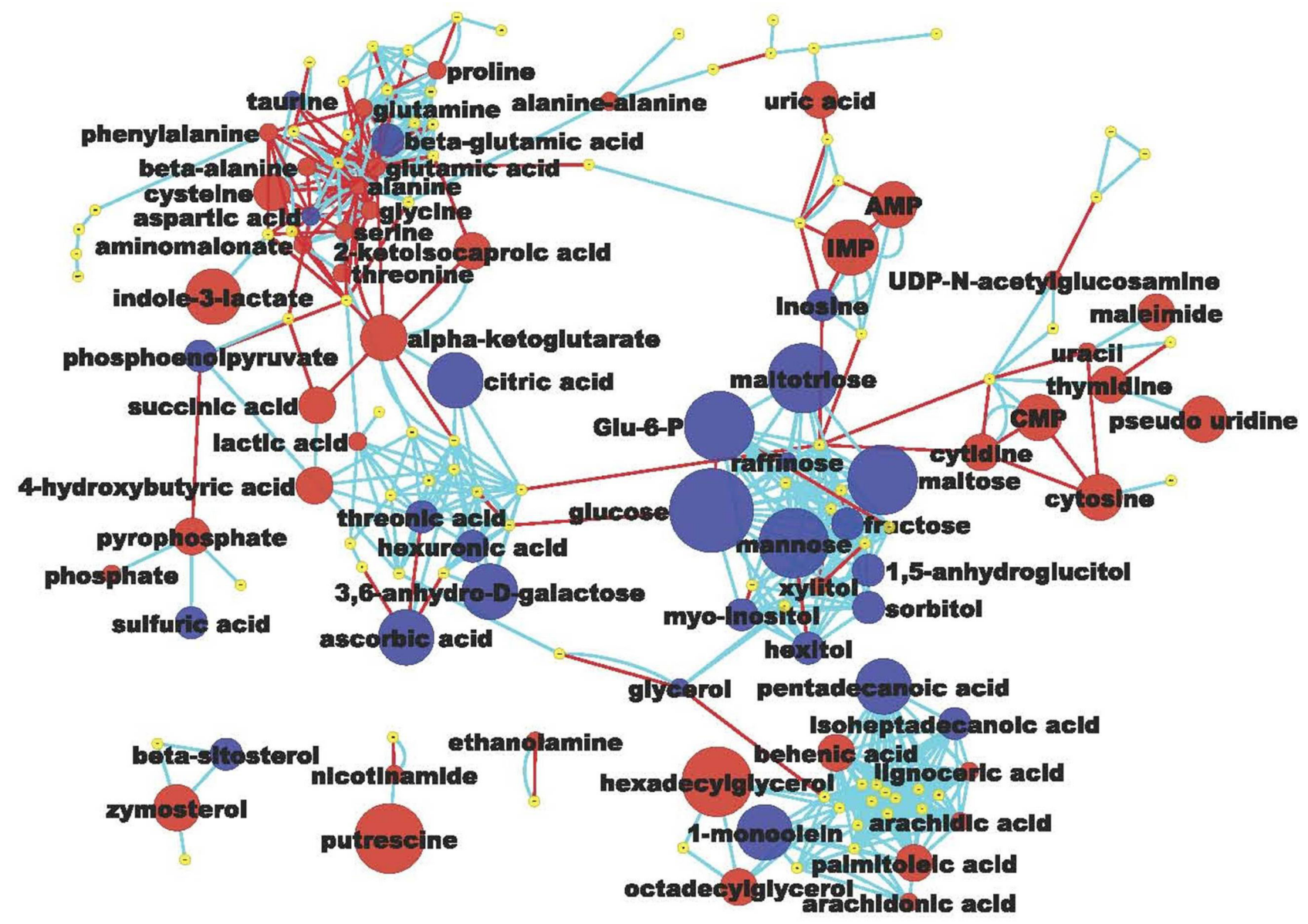

Figure 1: Metabolomic network of biochemical differences between hyperplastic Zn-deficient and Zn-sufficient esophagus. Each node represents an identified metabolite. Metabolites are connected based on biochemical relationships (red, KEGG RPAIRS) or structural similarity (light blue, Tanimoto coefficient $\geq 0.7$ ). Metabolite size reflects fold-change (ZD vs ZS); node color represents relative change (Blue, decrease, $P<0.05$; Red, increase, $P<0.05$; yellow, insignificant change) metabolite size reflects absolute fold change (Table 1). Labels are shown for the metabolites that pass the significance cutoff $(P<0.05)$ 
Table 1: Metabolomic signature in precancerous $\mathrm{Zn}$-deficient rat esophagus

\begin{tabular}{|c|c|c|c|}
\hline Metabolite name & \begin{tabular}{|c|} 
Fold change (ZD vs \\
$\mathrm{ZS})$
\end{tabular} & $P$-value & Biological process \\
\hline \multicolumn{4}{|l|}{27 down-regulated } \\
\hline glucose & -153 & 0.0002 & Glycolysis/gluconeogenesis \\
\hline maltose & -20 & 0.0002 & Starch \& sucrose metabolism \\
\hline maltotriose & -9.0 & 0.0002 & ATP-binding cassette transporters \\
\hline glucose-6-phosphate & -8.8 & 0.0011 & Glycolysis/pentose phosphate pathway \\
\hline mannose & -7.5 & 0.0011 & Fructose \& mannose metabolism \\
\hline 3,6-anhydro-D-galactose & -6.7 & 0.0100 & --- \\
\hline ascorbic acid & -6.1 & 0.0009 & Glutathione metabolism \\
\hline 1-monoolein & -5.9 & 0.0002 & --- \\
\hline citric acid & -5.3 & 0.0003 & Citrate cycle (TCA Cycle) \\
\hline pentadecanoic acid & -5.1 & 0.0002 & --- \\
\hline hexitol & -3.6 & 0.0002 & Fructose \& mannose metabolism \\
\hline beta-glutamic acid & -3.4 & 0.0022 & --- \\
\hline fructose & -3.4 & 0.0002 & Starch \& sucrose metabolism \\
\hline phosphoenolpyruvate & -3.3 & 0.0017 & Glycolysis/gluconeogenesis \\
\hline myo-inositol & -2.9 & 0.0001 & Galactose Metabolism \\
\hline sulfuric acid & -2.9 & 0.0012 & Purine metabolism \\
\hline isoheptadecanoic acid NIST & -2.9 & 0.0150 & --- \\
\hline beta-sitosterol & -2.8 & 0.0001 & Steroid biosynthesis \\
\hline threonic acid & -2.4 & 0.0018 & Ascorbate \& aldarate metabolism \\
\hline inosine & -2.3 & 0.0370 & Purine metabolism \\
\hline 1,5-anhydroglucitol & -2.2 & 0.0002 & --- \\
\hline sorbitol & -2.1 & 0.0019 & Fructose \& mannose metabolism \\
\hline hexuronic acid & -2.0 & 0.0003 & $\mid--$ \\
\hline raffinose & -1.9 & 0.0027 & Galactose metabolism \\
\hline aspartic acid & -1.8 & 0.0415 & Amino acid metabolism \\
\hline taurine & -1.7 & 0.0019 & Primary bile acid metabolism \\
\hline glycerol & -1.4 & 0.0085 & Galactose/glycerolipid metabolism \\
\hline \multicolumn{4}{|l|}{44 up-regulated } \\
\hline putrescine & 14 & 0.0100 & Glutathione/amino acid metabolism \\
\hline hexadecylglycerol NIST & 10 & 0.0002 & --- \\
\hline inosine 5'-monophosphate & 6.4 & 0.0063 & Purine metabolism \\
\hline indole-3-lactate & 5.5 & 0.0140 & Tryptophan degradation \\
\hline $\begin{array}{l}\text { cytidine-5-monophosphate } \\
\text { NIST }\end{array}$ & 4.7 & 0.0013 & Pyrimidine metabolism \\
\hline zymosterol & 3.7 & 0.0000 & --- \\
\hline alpha-ketoglutarate & 3.5 & 0.0380 & --- \\
\hline cytosine & 3.3 & 0.0002 & Pyrimidine metabolism \\
\hline adenosine-5-monophosphate & 3.0 & 0.0011 & Purine metabolism \\
\hline pseudo uridine & 3.0 & 0.0100 & Pyrimidine metabolism \\
\hline cytidine & 2.6 & 0.0003 & Pyrimidine metabolism \\
\hline cysteine & 2.4 & 0.0000 & Amino acid metabolism \\
\hline octadecylglycerol & 2.4 & 0.0030 & --- \\
\hline
\end{tabular}




\begin{tabular}{|c|c|c|c|}
\hline uric acid & 2.3 & 0.0100 & Purine metabolism \\
\hline succinic acid & 2.2 & 0.0070 & Citrate cycle (TCA cycle) \\
\hline thymidine & 2.1 & 0.0047 & Pyrimidine metabolism \\
\hline maleimide & 2.1 & 0.0067 & --- \\
\hline 2-ketoisocaproic acid & 2.1 & 0.0149 & Amino acid metabolism \\
\hline palmitoleic acid & 2.1 & 0.0030 & Fatty acid biosynthesis \\
\hline 4-hydroxybutyric acid & 2.1 & 0.0000 & Butanoate metabolism \\
\hline pyrophosphate & 2.0 & 0.0043 & Oxidative phosphorylation \\
\hline behenic acid & 2.0 & 0.0002 & Biosynthesis of unsaturated fatty acids \\
\hline aminomalonate & 1.8 & 0.0100 & --- \\
\hline beta-alanine & 1.8 & 0.0402 & Pyrimidine metabolism \\
\hline UDP-N-acetylglucosamine & 1.8 & 0.0047 & Amino sugar \& nucleotide sugar metabolism \\
\hline arachidic acid & 1.7 & 0.0001 & Biosynthesis of unsaturated fatty acids \\
\hline lactic acid & 1.7 & 0.0000 & Glycolysis, pyruvate metabolism \\
\hline alanine-alanine & 1.7 & 0.0011 & D-alanine metabolism \\
\hline ethanolamine & 1.7 & 0.0001 & --- \\
\hline xylitol & 1.6 & 0.0380 & Riboflavin metabolism \\
\hline lignoceric acid & 1.6 & 0.0044 & Biosynthesis of unsaturated fatty acids \\
\hline phosphate & 1.6 & 0.0037 & Oxidative phosphorylation \\
\hline arachidonic acid & 1.6 & 0.0150 & Biosynthesis of unsaturated fatty acids \\
\hline proline & 1.5 & 0.0124 & Amino acid metabolism \\
\hline phosphoethanolamine & 1.5 & 0.0438 & Glyerophospholipid metabolism \\
\hline uracil & 1.5 & 0.0395 & Pyrimidine metabolism \\
\hline glutamine & 1.4 & 0.0148 & Amino acid metabolism $\mathrm{C} / \mathrm{N}$ balance \\
\hline phenylalanine & 1.4 & 0.0132 & Amino acid metabolism \\
\hline serine & 1.4 & 0.0000 & Amino acid metabolism \\
\hline alanine & 1.3 & 0.030 & Amino acid metabolism \\
\hline glutamic acid & 1.3 & 0.001 & Amino acid metabolism \\
\hline nicotinamide & 1.3 & 0.021 & Energy metabolism \\
\hline threonine & 1.3 & 0.009 & Amino acid metabolism \\
\hline glycine & 1.3 & 0.001 & Amino acid metabolism \\
\hline
\end{tabular}

A group of 71 significantly altered metabolites were identified in ZD vs ZS esophagus using a cutoff point of P-value $\leq 5 \%$ and fold-change $\geq 1.3$ ( $\mathrm{n}=8$ rats/cohort). $\mathrm{ZD}=\mathrm{Zn}$-deficient; $\mathrm{ZS}=\mathrm{Zn}$-sufficient.

(59\%) were carbohydrates, including glucose, glucose-6phosphate, maltose, maltotriose, mannose, 3,6-anhydroD-galactose, and fructose. The remaining $41 \%$ were lipids (three), amino acids (three), nucleotide (one), sterol (one), organic acid (one), and others (two) (Figure 1 and Table 1). Most strikingly, glucose was decreased by 153-fold $(P<0.001)$. Glucose depletion was positively correlated with a 1.7-fold increase in lactic acid $(P<$ $0.001)$. This result indicates that the proliferating ZDesophageal cells vigorously consume glucose (resulting in glucose depletion), and produce lactic acid under aerobic conditions.

Because of the need to replicate all of its cellular contents, proliferating cells have a high biosynthetic demand for amino acids, lipids, and nucleotides. Thus, in cancer cells aerobic glycolysis fulfills the requirement to support cell proliferation rather than to generate energy in the form of adenosine 5'-triphosphate (ATP) [48]. The highly proliferative ZD esophagus showed a metabolic profile consistent with uncontrolled proliferation. Of the 44 up-regulated metabolites (Table 1 and Figure 1), many were involved in amino acid metabolism/ protein biosynthesis (putrescine, cysteine, beta-alanine, ethanolamine, proline, glutamine, phenylalanine, nicotinamide etc.), purine \& pyrimidine metabolism (inosine 5'-monophosphate, cytidine-5-monophosphate, adenosine-5-monophosphate, cytidine, uric acid, thymidine, phosphate), unsaturated fatty acids biosynthesis 
Table 2: Metabolomic profiling of esophageal mucosa from Zn-replenished rats at 72 hours after $\mathrm{Zn}$-replenishment as compared to $\mathrm{Zn}$-sufficient counterpart

\begin{tabular}{|c|c|c|c|}
\hline Metabolite name & Fold change (ZR vs ZS) & $P$-value & Biological process \\
\hline \multicolumn{4}{|l|}{13 down-regulated } \\
\hline glucose & -20 & 0.0006 & Glycolysis/gluconeogenesis \\
\hline pentadecanoic acid & -5.8 & 0.0002 & --- \\
\hline 3,6-anhydro-D-galactose & -3.7 & 0.0100 & ATP-binding cassette transporters \\
\hline maltose & -3.1 & 0.0104 & Starch \& sucrose metabolism \\
\hline sorbitol & -3.0 & 0.0002 & Fructose \& mannose metabolism \\
\hline linoleic acid & -2.2 & 0.0171 & Biosynthesis of prostaglandin \\
\hline beta-glutamic acid & -1.9 & 0.0371 & --- \\
\hline isoheptadecanoic acid NIST & -1.9 & 0.0210 & --- \\
\hline fumaric acid & -1.7 & 0.0100 & Citrate cycle (TCA cycle) \\
\hline hexuronic acid & -1.6 & 0.0135 & --- \\
\hline 1,5-anhydroglucitol & -1.5 & 0.0047 & --- \\
\hline beta-sitosterol & -1.5 & 0.0361 & Steroid biosynthesis \\
\hline N-acetylmannosamine & -1.4 & 0.0348 & Amino/nucleotide sugar metabolism \\
\hline \multicolumn{4}{|l|}{17 up-regulated } \\
\hline indole-3-lactate & 2.8 & 0.0031 & Tryptophan degradation \\
\hline ornithine & 2.2 & 0.0463 & Arginine biosynthesis \\
\hline tyrosine & 2.0 & 0.0003 & Amino acid metabolism \\
\hline proline & 1.7 & 0.0010 & Amino acid metabolism \\
\hline aminomalonate & 1.7 & 0.0100 & --- \\
\hline citrulline & 1.7 & 0.0011 & Arginine biosynthesis \\
\hline alanine-alanine & 1.7 & 0.0011 & D-alanine metabolism \\
\hline leucine & 1.7 & 0.0004 & Amino acid metabolism \\
\hline oxoproline & 1.6 & 0.0002 & --- \\
\hline phenylalanine & 1.6 & 0.0005 & Amino acid metabolism \\
\hline isoleucine & 1.6 & 0.0002 & Amino acid metabolism \\
\hline valine & 1.6 & 0.0002 & Amino acid metabolism \\
\hline methionine sulfoxide & 1.5 & 0.0054 & --- \\
\hline trans-4-hydroxyproline & 1.5 & 0.0108 & Amino acid metabolism \\
\hline glutamine & 1.5 & 0.0047 & Amino acid metabolism $\mathrm{C} / \mathrm{N}$ balance \\
\hline glycine & 1.4 & 0.0000 & Amino acid metabolism \\
\hline threonine & 1.4 & 0.0023 & Amino acid metabolism \\
\hline
\end{tabular}

A group of 30 significantly altered metabolites were identified in ZR vs ZS esophagus using a cutoff point of P-value $\leq 5 \%$ and fold-change $\geq 1.3$ ( $\mathrm{n}=8$ rats/cohort). $\mathrm{ZR}=\mathrm{Zn}$-replenished; $\mathrm{ZS}=\mathrm{Zn}$-sufficient

(hexadecylglycerol, octadecylglycerol, arachidonic acid, palmitoleic acid, arachidic acid), glycolysis (lactic acid), and energy metabolism (nicotinamide). Of these, the top up-regulated metabolite was the amino-acid derived putrescine (up 14-fold, $P<0.01$ ). High levels of polyamines, including putrescine, are associated with human cancers and cell proliferation through DNA packaging $[49,50]$. In summary, untargeted metabolomic profiling by GC-TOF MS revealed that the proliferative ZD esophageal mucosa exhibits extensive remodeling of metabolism, including a high rate of aerobic glycolysis accompanied by up-regulation of many metabolites that serve as building blocks for biomass synthesis.

\section{Reversal of cancer-associated metabolic profile by ZR}

To investigate the metabolic response following $\mathrm{Zn}$ replenishment, we performed metabolomic analysis 
by GC-TOF MS in restored esophageal mucosa from $\mathrm{ZR}$ rats at 72 hours after replenishing $\mathrm{Zn}$ ( $n=8$ rats). As shown Table 2, the number of significantly deregulated metabolites in ZR vs ZS esophagus was 30 (13 downregulated \& 17 up-regulated), which is $\sim 42 \%$ of that in ZD vs ZS esophagus (Table 1). In particular, glucose deregulation was improved from a down-regulation of 153-fold in ZD esophagus to 20-fold in ZR counterpart $(P<0.001$, Table 2$)$, as compared to ZS esophagus. Putrescine, the top-up-regulated metabolite in ZD esophagus was returned to ZS status. These metabolomic results mirror those of transcriptomic data, in which, shortly after ZR the altered gene expression rapidly reverted to near control ZS levels, accompanied by reduced cell proliferation, increased apoptosis, and a reversal of the hyperplastic esophageal phenotype $[16,17$, 20].

\section{Integration of metabolomics, transcriptomics, and miRNA profiling dataset}

To identify a key deregulated biochemical and molecular signaling network in ZD-induced esophageal preneoplasia, we integrated metabolomics with transcriptomics of ZD esophagus from a study of identical design [16]. Previous microarray analysis by Affymetrix rat genome 2302.0 GeneChip identified a total of 2305 significantly deregulated genes in the hyperplastic ZD vs ZS esophagus (fold change $\geq 2$ ) from rats after a 6-week dietary regimen [16]. A gene-metabolite integration network (Supplementary Figure 1) was calculated by queries in ZD vs ZS esophagus from the 2,305 deregulated genes [16] and 71 significantly deregulated metabolites (Table 1) and mapping with $\log 2$ fold-change using the GRINN database within the metabox toolbox [51]. Several metabolic pathways showed significant alterations at both the transcriptional and metabolic levels (Supplementary Figure 1). As examples, connections that occur between specific gene and metabolite were observed between $H k 2$ up-regulation \& glucose down-regulation; cytochrome P450 genes (Cyp4b1, Cyp4f6, Cyp2a1) down-regulation \& arachidonic acid up-regulation; Atp2a2, Atp1a2 down-regulation/Atp 7a, Dusp 1, Pfkfb3 up-regulation \& phosphate $\left(\mathrm{O}_{4} \mathrm{P}^{-3}\right)$ up-regulation; Gfpt 2 down-regulation \& L-glutamine/L-glutamic acid up-regulation.

We focused our study on HK2-glucose link because of its critical role in cancer metabolism [32]. Strikingly, $H K 2$ that was up-regulated 3.9-fold in hyperplastic ZD vs

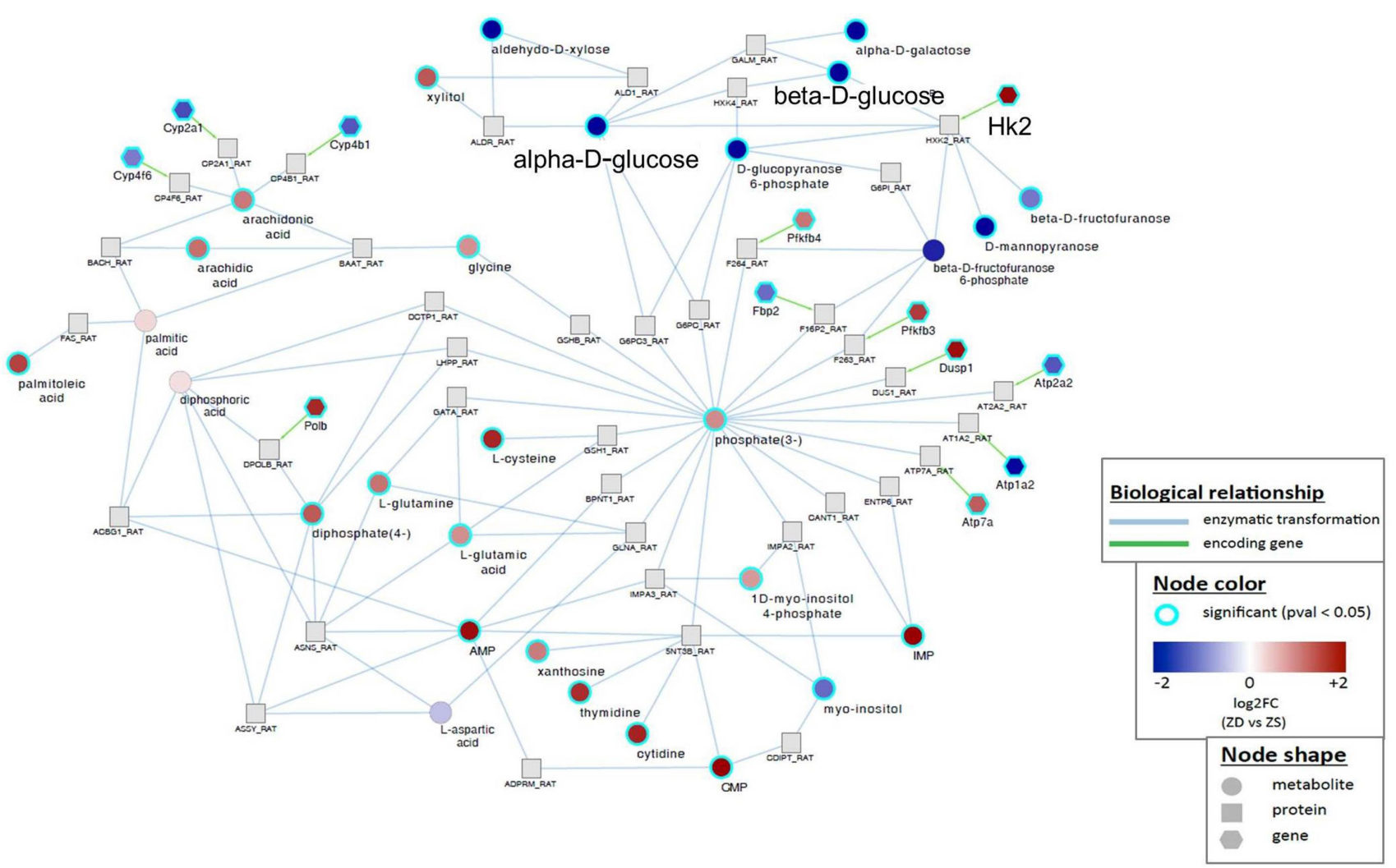

Figure 2: Gene-metabolite integration network in Zn-deficient versus Zn-sufficient esophagus reveals a direct connection between $\boldsymbol{H} \boldsymbol{k} \mathbf{2}$ up-regulation and decreased level of glucose metabolite. Biological relationship - blue, enzymatic transformation; green, encoding gene. Node shape represents metabolite, protein, or gene. Node color represents fold change (ZD vs ZS) and $P<0.05$. 

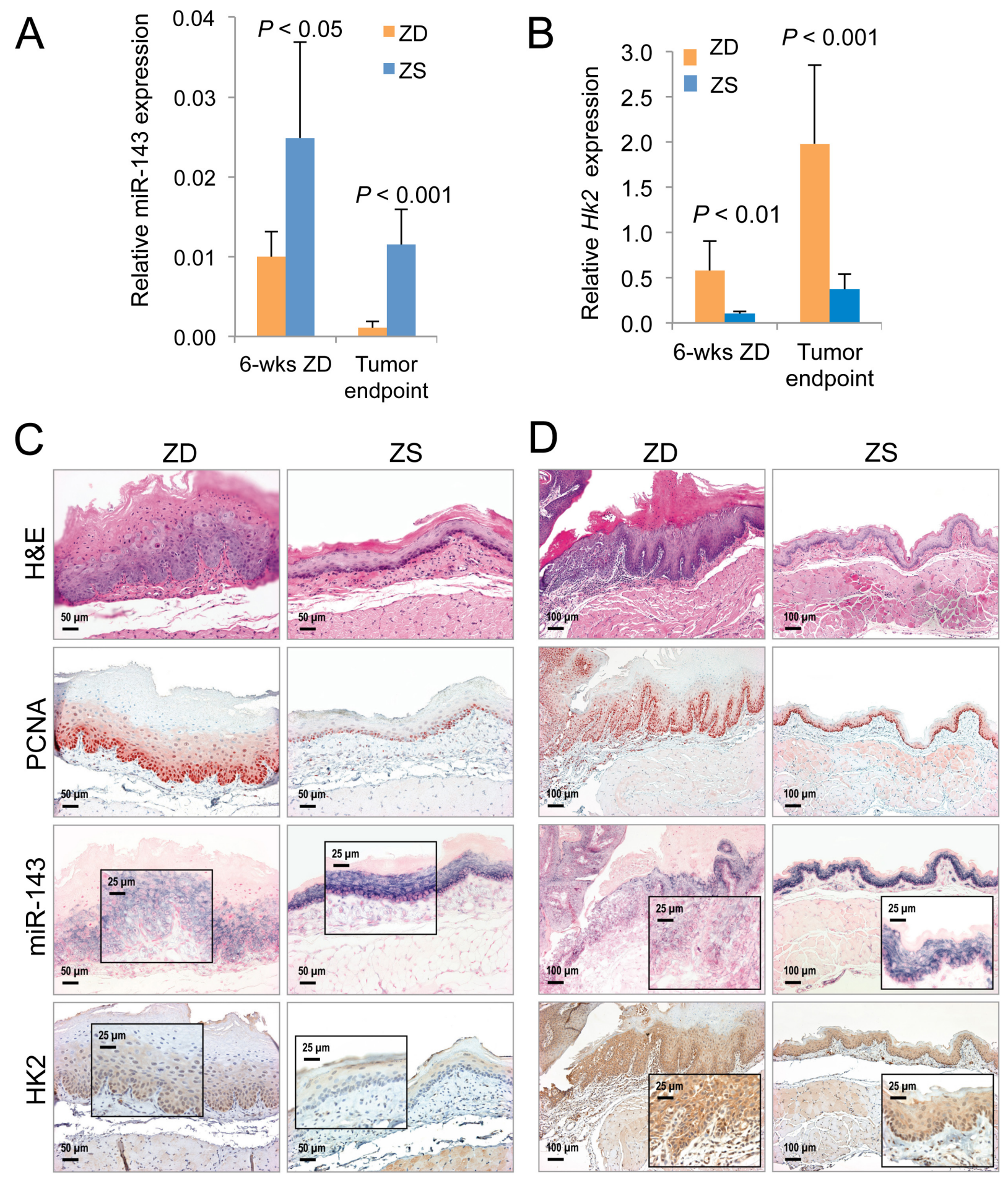

Figure 3: Analysis of cell proliferation, miR-143 and HK2 expression in Zn-deficient preneoplastic and neoplastic rat esophageal tissues. A. qPCR analysis of miR-143 (U87 as normalizer, $n=8$ rats/group; results are shown as means, error bars represent standard deviation). B. qPCR analysis of mRNA expression of $H K 2$ (Psmb6 as normalizer, $n=8$ rats/group; results are shown as means, error bars represent standard deviation). Analysis of miR-143 and HK2 expression by in situ hybridization (ISH) and immunohistochemistry (IHC) in formalin fixed paraffin embedded esophageal samples in - C. ZD versus ZS esophagus after a 6-week dietary regimen $(n=$ 8 rats/group) D. Archived samples of ESCC-bearing ZD esophagus versus tumor-free control ZS esophagus [28] ( $n=10$ rats/group). Representative hematoxylin and eosin [H\&E]-stained and PCNA-stained sections are shown. miR-143 ISH signal (blue, 4-nitro-blue tetrazolium and 5-brom-4-chloro-3'-indolylphosphate; counterstain, nuclear fast red). HK2 expression (brown, 3,3'-diaminobenzidine tetrahydrochloride, counterstain, Harris modified hematoxylin). Scale bars: $50 \mu \mathrm{m}$ (x200 magnification), $100 \mu \mathrm{m}$ (x100 magnification, and $25 \mu \mathrm{m}$ (x400 magnification, inset). 
ZS esophagus by microarray expression analysis [16] was directly connected to down-regulated glucose metabolites, namely, alpha-D-glucose and beta-D-glucose (Figure 2). The HK2 enzyme catalyzes the first committed step in glucose metabolism where glucose is phosphorylated to yield glucose-6-phosphate. In mammals there are four hexokinase isoforms, HK1, HK2, HK3, and HK4 (also known as glucokinase). Only HK2 is expressed at high levels in cancer cells $[52,53]$, thus accounting for the high glycolytic rate in cancer cells [54]. Thus, by combining metabolomics and transcriptomics, we have identified an aerobic glycolysis network that involves HK2 and glucose signaling associated with uncontrolled cell proliferation in early esophageal cancer development induced by dietary ZD.

Using the NanoString miRNA expression profiling platform, we previously reported that prolonged ZD (22 weeks) induced extensive alterations in miRNA expression in the hyperplastic ZD esophagus, and many of the dysregulated miRNAs are similarly altered in human ESCC [28]. In a search for known miRNAs that regulate HK2, we examined this published miRNA profiling data for ZD esophagus [28]. Significantly, miR-143, a tumor suppressor in human cancers, including ESCC [55, 56], and a known negative regulator of $H K 2$ [36], was downregulated 1.8 -fold $(P=0.0136)$ in the highly proliferative $\mathrm{ZD}$ esophagus as compared to its non-proliferative counterpart vs ZS [28]. Based on this observation, we went on to perform Taqman miRNA assays using qPCR and showed that the tumor suppressor miR-143 was downregulated 2.5-fold in hyperplastic ZD vs ZS esophagus from rats after a brief 6-week dietary regimen $(P<0.05, n$ $=8$ rats/group $)$, and down-regulated 10 -fold $(P<0.001, n$ $=8$ rats/group) in archived samples of ESCC-bearing ZD esophagus vs non-ESCC-bearing ZS counterpart from an esophageal tumor study in $\mathrm{Zn}$-modulated rats [28]. In an inverse manner, qPCR analysis showed that $H k 2$ mRNA levels were significantly up-regulated in these same ZD tissues (up 5.8-fold in hyperplastic ZD vs ZS esophagus $\&$ up 5.4-fold in archived samples [28] of ESCC-bearing ZD esophagus $v$ non-ESCC-bearing ZS esophagus $(P<$ 0.01 to $P<0.001, n=8$ rats/group) (Figure $3 \mathrm{~B}$ ). Thus, integration of metabolomics with transcriptomics [16] \& microRNA profiling data [28] in the hyperplastic ZD esophagus revealed that deregulated glucose uptake is accompanied by miR-143 down-regulation and upregulation of the hexokinase gene $H k 2$. This result is consistent with reports that miR-143 is an essential regulator of cancer glycolysis by targeting HK2 in cancer cells, including lung cancer, head and neck squamous cell carcinoma, renal cell carcinoma, and colon cancer cells [36-39].

\section{Divergent inverse correlation of miR-143 \& HK2 expression in nonproliferative esophagus vs proliferative ZD esophageal neoplasia and human ESCC}

To understand the distribution and localization of miR-143 in esophageal neoplasia in relation to localization of its target HK2 protein and the level of cell proliferation, we performed in situ hybridization (ISH) and immunohistochemical staining (IHC) on near serial sections of rat esophageal tissues ( $n=10$ rats/group), as well as in the archived human ESCC tissues for which we previously reported overexpression of miR-31, -21, -223 [27, 28]. Cellular origin of miR-143 was defined by ISH using high affinity double Dig-labeled LNA probes (Exiqon, Vedbaek, Denmark). Localization of HK2 protein and the cell proliferation marker PCNA [56] were evaluated by IHC.

Both nonproliferative ZS esophagus (after a 6-week dietary regimen) and non-ESCC-bearing ZS rat esophagus (from an esophageal tumor study) showed few PCNA-positive nuclei, mostly restricted to basal cell layer (Figure 3C and 3D). Concurrently, these ZS tissues showed abundant and intense miR-143 ISH signal in basal and suprabasal cell layers along with weak HK2 protein expression. This finding indicates that robust expression of this miRNA suppresses HK2 expression, effects that support normal cell growth. By contrast, the highly proliferative preneoplastic ZD esophagus, as well as ESCC-bearing ZD esophagus displayed a high rate of cell proliferation with abundant PCNA-positive nuclei in many cell layers. At the same time, both preneoplastic and cancerous phenotypes exhibited weak/diffuse miR-143 ISH signals but moderate/strong cytoplasmic HK2 expression (Figure 3C and 3D), indicating downregulation of the tumor suppressor, miR-143, leads to overexpression of HK2 and enhanced cell proliferation/ ESCC development. Together, these data revealed for the first time the opposing inverse-correlation between miR143 \& HK2 expression in normal esophagus with limited cell growth (ZS esophagus) and precancerous/cancerous ZD esophageal cells with unbridled cell proliferation.

Using the same human ESCC tissues in which we previously documented overexpression of miR-31, miR21 , miR-223 by ISH [28], Figure 4 shows these human ESCC tissues were also highly proliferative with numerous PCNA-positive nuclei ( $n=12$ cases). While miR-143 ISH signals were absent in human ESCC tissues, strong cytoplasmic HK2 protein expression was present (Figure 4). This result is typical of all 12 patients studied and is consistent with that in the ZD preneoplastic/cancerous esophageal tissues. 


\section{Human esophageal squamous cell carcinoma}
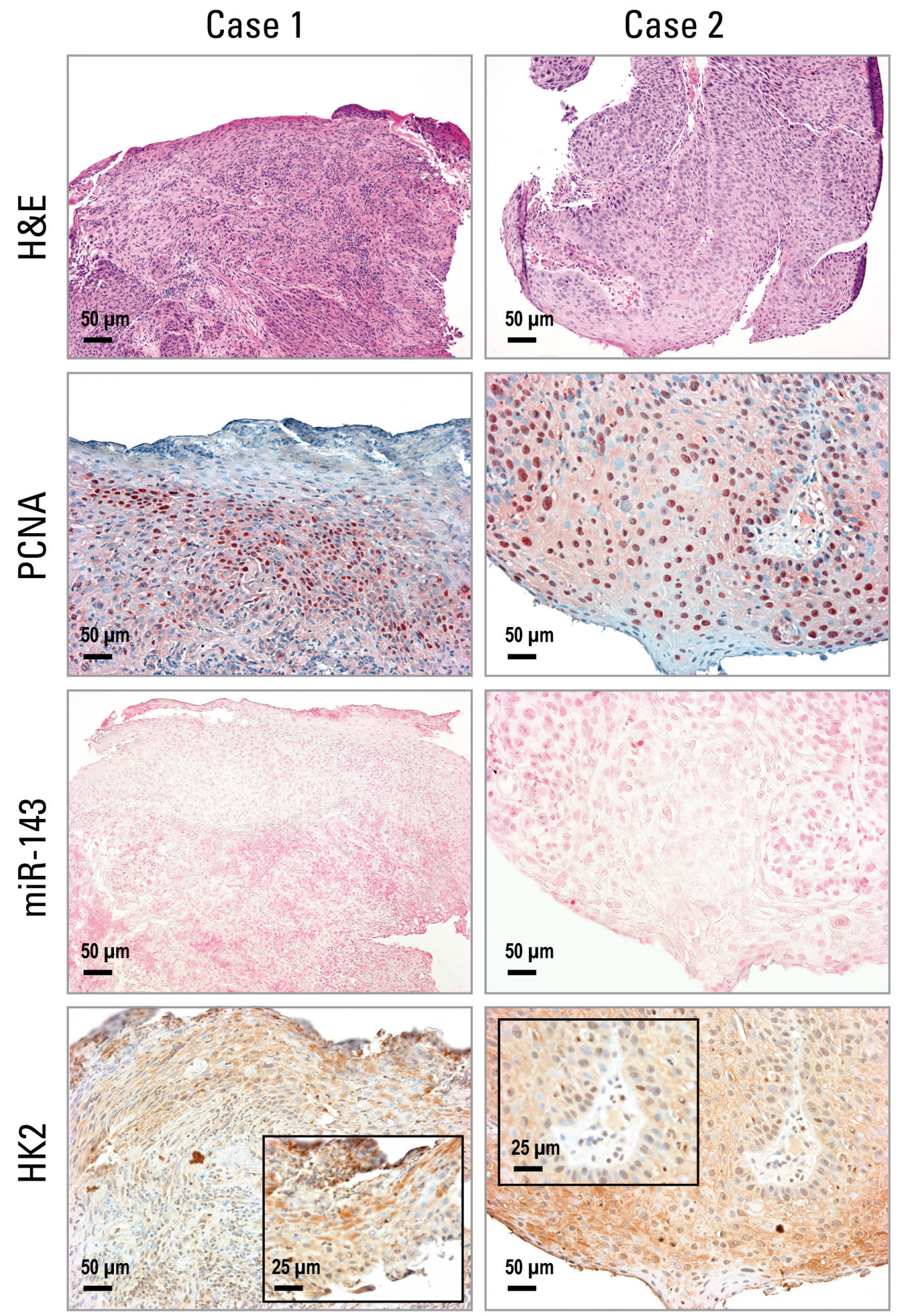

Figure 4: Analysis of cell proliferation, miR-143 and HK2 expression in human esophageal squamous cell carcinoma (ESCC) tissue by in situ hybridization and immunohistochemistry. Representative hematoxylin and eosin [H\&E]-stained and PCNA-stained ESCC tissues (2 cases are shown). miR-143 ISH signal (blue, 4-nitro-blue tetrazolium and 5-brom-4-chloro-3'indolylphosphate; counterstain, nuclear fast red) was absent in ESCC tumor area. HK2 expression (brown, 3,3'-diaminobenzidine tetrahydrochloride) was moderate to strong in near serial formalin-fixed, paraffin-embedded sections of ESCC tumor tissue (Case $1 \& 2$ ). Scale bars: $50 \mu \mathrm{m}$ (x200 magnification), and $25 \mu \mathrm{m}$ (x400 magnification, inset) $(n=12$ cases). 


\section{DISCUSSION}

In the current study, untargeted metabolomic profiling by GC-TOF MS showed that the highly proliferative ZD rat esophagus has a distinct cancerassociated metabolomic signature as compared with nonproliferative ZS counterpart (Table 1). Glucose downregulation (153-fold, $P<0.001)$ was accompanied by up-regulation of lactic acid (1.7-fold, $P<0.001)$, a result indicating a high rate of aerobic glycolysis (the Warburg effect), a common feature of cancer cell metabolism. At the same time, almost all of the 44 metabolites that were up-regulated were intermediate precursors needed for amino acid metabolism/protein biosynthesis, purine $\&$ pyrimidine metabolism, or lipid biosynthesis. These finding emphasize the requirement of cell proliferation to provide building blocks to support de novo biosynthesis needed to produce new cells [48]. Importantly, the dysregulated metabolites, including glucose, were highly Zn-responsive. Zn-replenishment rapidly increased glucose content and restored many deregulated metabolites to control levels (Table 2), accompanied by reversal of the hyperplastic phenotype. Taken together, the metabolomic data establish for the first time that the nutrient, $\mathrm{Zn}$, regulates cancer metabolism in esophageal neoplasia development and reversal. This result is consistent with the ZR effect on the reversal of altered gene expression in esophageal neoplasia [16, 17].

To date, there are only a few metabolomic profiling studies in human ESCC; most of which were performed on biofluids from ESCC patients (plasma, serum, and urine). Only one study was conducted on human ESCC tissues $v s$ normal mucosae using nuclear magnetic resonance, where glucose down-regulation and up-regulation of short-chain fatty acid were correlated with the stage of ESCC [57], consistent with our metabolomic profile of the preneoplastic rat esophagus induced by ZD.

Human cancers have been extensively profiled by transcriptomic- and miRNA-based studies and increasingly by metabolic profiling, owing to recent advances in metabolomic platforms. Efforts to integrate these multilevel events to form gene-metabolite networks have led to a better understanding of the molecular basis of cancer. In the current study, to decipher the mechanism underlying aberrant glucose metabolism induced by dietary ZD in the earliest stage of esophageal carcinogenesis, we performed an integrated analysis of metabolomics with our published transcriptomics for preneoplastic ZD rat esophagus [16]. This analysis uncovers a direct link between glucose down-regulation and up-regulation of the glycolytic enzyme HK2 (Figure 2). HK2 catalyzes the first step of glycolysis and is overexpressed in many human cancers, including ESCC. Several other enzymes in glycolysis are also increased in cancer cells, but unlike HK2 they are also expressed in normal cells [58]. Genetic deletion of HK2 has been reported to reduce the overall tumor burden in lungs in a genetic mouse lung cancer model, indicating a role of HK2 in tumor initiation [58]. In patients with ESCC, a positive correlation is well established between a high ${ }^{18} \mathrm{~F}-\mathrm{FDG}$ uptake (a marker for tissue uptake of glucose) and HK2 activity in resected specimen $[59,60]$. Thus, our finding of a HK2-glucose link in hyperplastic ZD esophagus highlights the critical role of HK2 in deregulated glucose metabolism in early esophageal tumor development by ZD.

It is now well recognized that miRNAs play a critical role in regulating cellular metabolism in health and disease, including cancer, thereby generating a bidirectional functional link in the crosstalk between miRNA and metabolism [34, 61]. The most pronounced metabolic alteration in cancer cells is deregulated uptake of glucose and associated aerobic glycolysis [14, 32]. Critical to cancer aerobic glycolysis is the glycolytic enzyme HK2 that catalyzes the first committed step in glycolysis [54]. In this study, integrated analysis of -omics datasets with miRNA expression profiling revealed a miR-143-HK2glucose link in hyperplastic ZD esophagus. Moreover, we showed that miR-143 regulates cancer glycolysis in ZDinduced esophageal neoplasia by targeting HK2 (Figure 3 ), a result consistent with reports for lung cancer, renal cell carcinoma, head and neck squamous cell carcinoma, breast cancer, and prostate cancer [36-38, 62, 63].

A limitation of this current study is the fact that only the HK2-glucose gene-metabolite network is studied in detail. Future studies are needed to investigate other gene-metabolite connections in our integrated analysis of metabolomics and transcriptomics (Figure 2, Supplementary Figure 1). In addition, future studies are needed to unravel the mechanism(s) whereby dietary ZD regulates the expression of miR-143.

In summary, our metabolomic profiling reveals that increased consumption of glucose is the most prominent metabolic alteration in the highly proliferative $\mathrm{ZD}$ esophagus. The finding that ZR rapidly corrects aberrant metabolite levels, including that of glucose, indicates that $\mathrm{Zn}$ regulates glucose metabolism in esophageal cancer initiation and reversal. Integration of metabolomics with our published transcriptomics and microRNA profiling data revealed a miR-143-HK2-glucose pathway that underlies esophageal neoplasia by ZD. The finding shows that to support cell proliferation, ZD reprograms glucose metabolism by modulating the expression of miR-143, which targets HK2. Altogether, our data advance the understanding of the mechanistic role of $\mathrm{Zn}$ in ESCC development and prevention.

\section{MATERIALS AND METHODS}

\section{Rat studies}

The Animal protocol was approved by the Thomas Jefferson University Animal Care and Use Committee. 
Male weanling Sprague-Dawley rats $(50 \pm 5 \mathrm{~g})$ were obtained from Taconic Laboratory (Germantown, NY). Custom-formulated ZD and ZS diets (Harlan Teklad, Madison, WI) were identical except for the amount of zinc, which was 3-4 ppm for ZD and $\sim 60 \mathrm{ppm}$ for ZS diet. Weanling male rats $(n=48)$ were fed a ZD $(n=32)$ or ZS $(n=16)$ diet for 6 weeks to establish esophageal proliferation in $Z D$ rats $[16,20,27]$. ZD rats were fed ad libitum and ZS rats were pair-fed to ZD animals to match the decreased food consumption of $Z D$ rats $[16$, $20,27]$. After 6 weeks ZD rats evidenced increased cell proliferation in the esophagus, as assessed by increased expression of proliferating cell nuclear antigen PCNA [15]. Zinc gluconate (1.0 mg elemental zinc) in saline was then administered intragastrically to $16 \mathrm{ZD}$ rats, which were immediately switched to the ZS diet to form the ZR group. At 72 hours after replenishment, all animals (ZD, ZR, and ZS, $n=16$ rats/group) were killed. Whole esophagus was excised and collected onto ice to minimize further metabolism. Esophageal epithelia ( $n=10$ rats/ group) were prepared by using a blade to remove the submucosal and muscularis layers, snap-frozen in liquid nitrogen, and stored at $-80^{\circ} \mathrm{C}[16,64]$. The remaining esophageal samples were fixed in $10 \%$ buffered formalin and paraffin embedded.

\section{GC TOF MS data acquisition and processing}

For metabolomic profiling, frozen esophageal samples from $\mathrm{ZD}, \mathrm{ZS}$, and $\mathrm{ZR}$ rats $(n=8$ rats per group; $20 \mathrm{mg}$ per esophagus) were shipped on dry ice to the NIH West Coast Metabolomics Center, University of California, Davis. Esophageal tissue was extracted and derivatized as described [40, 42]. For primary metabolites analysis by GC-TOF MS, the cold injection/automatic liner exchange gas chromatography-time of flight mass spectrometry (CIS-ALEX GC-TOF MS, Leco Pegasus IV) was employed using chromatographic and mass spectrometric parameters as previously described [40, 42]. From around 800 individual peaks detected per chromatogram, 353 genuine metabolites remained after extensive cleanup and filtering through the BinBase metabolomic database. Using the Fiehnlib libraries of over 1,200 mass spectra and retention indices for identified metabolites, 155 compounds per studies were be structurally identified by matching mass spectra and retention indices to authentic standards (MSI [65] level 1 identifications) or annotated by very high mass spectral similarities to the NIST14 library and close retention time predictions (MSI level 2 identifications, name followed by the label "NIST" in the Tables 1 and 2). A quality control sample for extracts was prepared by mixing small biofluid $(\sim 5 \mu \mathrm{l})$ of each sample in a study set, thus providing a sample with the true representation of the breadth of metabolites present in the sample set.

\section{Statistical analysis}

For analysis involving only 2 sets of data, a student's $t$-test or welch $t$-test was used depending on a F-test for differences in variance. For analysis involving multiple comparisons of all 3 groups (ZD, ZS and ZR), a ShapiroWilk Normality test was performed for each group. If any group failed the normality test, an overall Kruskal-Wallis chi-squared test was performed to test if there were any differences among the groups. A significant Kruskal-Wallis result was followed by pairwise Wilcoxon rank sum test to identify the differences between individual groups. In the case where no group failed the normality test, the Levene's homogeneity of variance test was performed. For datasets that were homoscedastic, a standard one-way ANOVA for overall differences was performed, followed by the Tukey HSD pot-hoc $t$-test for determination of differences among the groups. For heteroscedastic data, a Welch one-way ANOVA was performed, followed by the Games-Howell post hoc $t$-test for determination of differences among the groups. Statistical tests were 2-sided and were considered significant at $P \leq 0.05$. Statistical analysis was performed using R (http://www.R-project.org).

\section{Metabolome network visualization}

Network analysis was used to investigate statistical and multivariate modeling results within a biochemical context. A biochemical and chemical similarity network [45] was calculated for all measured metabolites with KEGG [46] and PubChem CIDs [47]. Enzymatic interactions were determined based on product-precursor relationships defined in the KEGG RPAIR database. Molecules not directly participating in biochemical transformations, but sharing many structural properties, based on PubChem Substructure Fingerprints [66], were connected at a threshold of Tanimoto similarity coefficient $\geq 0.7$.

The table of metabolites (nodes) and network properties ( $p$-values, direction of change) provided by MetaMapp were imported into the Cytoscape software and networks were generated by the organic layout algorithm in Cytoscape. Red and blue nodes show the increase and decrease in the amounts of metabolites, respectively. The blue lines reflect chemical similarity and red lines show biochemical reactions. Labels are not shown for metabolites that did not pass significance tests.

\section{Integrating metabolomics with gene expression data}

A genomics/metabolomics integration network from the data the metabolic profile in ZD rat esophagus was integrated with our published transcriptome dataset for this 
tissue ( $>2300$ dysregulated genes, identical study design as metabolomics data) [16]. The network contains genes, proteins and metabolites. It was queried from significant genes and metabolites $(P$-value $<0.05)$ and mapped with $\log 2$ fold-change.

\section{Integrating gene expression data with miRNA profiling data}

To find known miRNAs that regulate HK2, we searched our published miRNA profiling data for $\mathrm{ZD}$ esophagus [28].

\section{Rat esophageal samples for qPCR, TaqMan miRNA assay, ISH \& IHC assays}

For analyses involving 6 wks-ZD esophagus, esophageal tissues from the current metabolomic profiling study were used. For analyses involving esophageal tumor endpoint, archived samples of ESCC-bearing ZD esophagus and tumor-free control ZS esophagus from a previous study [28] were employed.

\section{RNA isolation}

Esophageal epithelial samples frozen in liquid nitrogen were pulverized to a fine powder using a chilled hammer. Total RNA was extracted from the pulverized samples using an animal tissue RNA extraction Kit (\#25700, Norgen Biotek, Ontario, Canada). RNA concentration of each sample was determined using a NanoDrop 1000 (Thermo Scientific). All RNA samples displayed a 260:280 ratio $>1.8$, and a 260:230 ratio $>1.8$.

\section{qPCR}

cDNA was reverse transcribed using the HighCapacity cDNA Archive Kit (Applied Biosystems, Foster City, CA) according to the manufacturer's protocol. qPCR was performed using pre-designed probes (Applied Biosystems), Psmb6 and Oaz1 as the normalizers, and the comparative $\mathrm{Ct}$ method.

\section{TaqMan miRNA assay}

Reverse transcription of miRNAs was performed according to the manufacturer's instructions (Applied Biosystems, Foster City, CA) with a reaction volume of $15 \mu \mathrm{l}$ containing $350 \mathrm{ng}$ of total RNA. Real-time qPCR was performed using StepOnePlus Real-time System (Applied Biosystems). Each miRNA and endogenous control (snoRNA and U87) was measured in triplicates. As an overall quality control, $\mathrm{Ct}$ (cycle threshold) values above 35 were excluded from analysis.

\section{Human ESCC samples}

Twelve cases of FFPE human ESCC samples were obtained from Thomas Jefferson University Hospital (Philadelphia, PA).

\section{In situ hybridization}

miRCURY locked nucleic acid (LNA) ${ }^{\mathrm{TM}}$ microRNA detection probes, namely, hsa-miR-143, rno-miR-31, and negative controls were purchased from Exiqon (Vedbaek, Denmark). The oligonucleotides are double DIG-labeled at the 5'- and 3'-ends. ISH was performed on $6 \mu \mathrm{m} \mathrm{FFPE}$ sections as previously described [26-28]. Following deparaffinization, rehydration in graded alcohol and proteinase $\mathrm{K}$ treatment, tissue sections were hybridized with miR-143 probe $(20 \mathrm{nM})$, in hybridization buffer (Exiqon) at $57^{\circ} \mathrm{C}$ for $14 \mathrm{~h}$ in a hybridizer (Dako, Glostrup, Denmark). Following stringent washes in SSC buffers, the sections were blocked against unspecific binding of the detecting antibody, using DIG wash and blocking reagent. miRNA was localized by incubation with 4-nitro-blue tetrazolium (NBT) and 5-brom-4-chloro-3'indolylphosphate (BCIP) (Roche, Mannheim, Germany). Nuclear fast red (Vector Lab., Burlingname, CA) was used as a counterstain.

\section{Immunohistochemistry (IHC)}

FFPE tissues were deparaffinized, and rehydrated in graded alcohols. IHC was carried out as previously described [20, 27], using anti-hexokinase 2 antibody [3D3] (\#NBP1-51643, mouse monoclonal, Novus Biologicals, Littleton, CO, USA) and PCNA antibody (clone PC-10, Ab-1, Thermo Scientific, Waltham, MA, USA), after citrate-based antigen retrieval. Protein was localized by incubation with 3-amino-9-ethylcarbazole substrate-chromogen (Dako, Carpinteria, CA, USA) or 3,3'-diaminobenzidine tetrahydrochloride (Sigma-Aldrich, St Louis, MO, USA).

\section{Microscopy}

IHC and ISH analyses were performed by light microscopy using an Olympus BX51 microscope and photographs taken with a Spot RT3 camera and Spot software v. 4.6.

\section{Zn content analysis}

Serum $\mathrm{Zn}$ content is determined by atomic absorption spectrometry [16]. 


\section{Author contributions}

L.Y.F. conceived \& supervised the project; R.J. provided technical assistance with animal maintenance \& performed laboratory assays; K.J.S. performed statistical analyses; C.T. contributed to transcriptomics dataset, H.A. contributed to NanoString miRNA dataset, J.F. and D.K.B. generated metabolomics network figures; O.F. provided supervision of metabolomic profiling; L.Y.F., J.L.F., and O.F. wrote the paper; C.M.C. provided resources \& edited manuscript.

\section{ACKNOWLEDGMENTS}

We thank K. Huebner for critical reading of the manuscript and helpful suggestions.

\section{CONFLICTS OF INTEREST}

The authors have no conflicts of interest to declare.

\section{FUNDING}

This work was supported by grants from the National Institutes of Health (CA118560 to LYF; R35CA197706 to CMC), American Institute for Cancer Research (Grant \#207232 to LYF), the NIH West Coast Metabolomics Center (U24 DK097154 to OF), and funds from the Department of Pathology, Anatomy \& Cell Biology, Thomas Jefferson University.

\section{REFERENCES}

1. Ferlay J, Soerjomataram I, Dikshit R, Eser S, Mathers C, Rebelo M, Parkin DM, Forman D, Bray F. Cancer incidence and mortality worldwide: sources, methods and major patterns in GLOBOCAN 2012. Int J Cancer. 2015; 136:E359-86.

2. Maret W, Sandstead HH. Zinc requirements and the risks and benefits of zinc supplementation. J Trace Elem Med Biol. 2006; 20:3-18.

3. Maret W. Zinc and human disease. Met Ions Life Sci. 2013; $13: 389-414$.

4. Kelleher SL, McCormick NH, Velasquez V, Lopez V. Zinc in specialized secretory tissues: roles in the pancreas, prostate, and mammary gland. Adv Nutr. 2011; 2:101-11.

5. Caulfield LE, Black RE. Zinc deficiency. In: Ezzati M, Lopez AD, Rodgers A, Murray CJ, editors. Comparative Quantification of Health Risk. Geneva, Switzerland: World Health Organization; 2004. pp. 257-80.

6. Prasad AS. Impact of the discovery of human zinc deficiency on health. J Am Coll Nutr. 2009; 28:257-65.

7. Sandstead HH. Zinc deficiency. A public health problem? Am J Dis Child. 1991; 145:853-59.
8. Prasad AS, Beck FW, Doerr TD, Shamsa FH, Penny HS, Marks SC, Kaplan J, Kucuk O, Mathog RH. Nutritional and zinc status of head and neck cancer patients: an interpretive review. J Am Coll Nutr. 1998; 17:409-18.

9. Kmet J, Mahboubi E. Esophageal cancer in the Caspian littoral of Iran: initial studies. Science. 1972; 175:846-53.

10. Yang CS. Research on esophageal cancer in China: a review. Cancer Res. 1980; 40:2633-44.

11. Abnet CC, Lai B, Qiao YL, Vogt S, Luo XM, Taylor PR, Dong ZW, Mark SD, Dawsey SM. Zinc concentration in esophageal biopsy specimens measured by $\mathrm{x}$-ray fluorescence and esophageal cancer risk. J Natl Cancer Inst. 2005; 97:301-06.

12. Vallee BL, Falchuk KH. The biochemical basis of zinc physiology. Physiol Rev. 1993; 73:79-118.

13. Berg JM, Shi Y. The galvanization of biology: a growing appreciation for the roles of zinc. Science. 1996; 271:108185.

14. Hanahan D, Weinberg RA. Hallmarks of cancer: the next generation. Cell. 2011; 144:646-74.

15. Fong LY, Li JX, Farber JL, Magee PN. Cell proliferation and esophageal carcinogenesis in the zinc-deficient rat. Carcinogenesis. 1996; 17:1841-48.

16. Taccioli C, Wan SG, Liu CG, Alder H, Volinia S, Farber JL, Croce CM, Fong LY. Zinc replenishment reverses overexpression of the proinflammatory mediator S100A8 and esophageal preneoplasia in the rat. Gastroenterology. 2009; 136:953-66.

17. Taccioli C, Chen H, Jiang Y, Liu XP, Huang K, Smalley KJ, Farber JL, Croce CM, Fong LY. Dietary zinc deficiency fuels esophageal cancer development by inducing a distinct inflammatory signature. Oncogene. 2012; 31:4550-58.

18. Mantovani A, Allavena P, Sica A, Balkwill F. Cancerrelated inflammation. Nature. 2008; 454:436-44.

19. Gebhardt C, Németh J, Angel P, Hess J. S100A8 and S100A9 in inflammation and cancer. Biochem Pharmacol. 2006; 72:1622-31.

20. Fong LY, Nguyen VT, Farber JL. Esophageal cancer prevention in zinc-deficient rats: rapid induction of apoptosis by replenishing zinc. J Natl Cancer Inst. 2001; 93:1525-33.

21. Calin GA, Croce CM. MicroRNA signatures in human cancers. Nat Rev Cancer. 2006; 6:857-66.

22. He L, Thomson JM, Hemann MT, Hernando-Monge E, $\mathrm{Mu}$ D, Goodson S, Powers S, Cordon-Cardo C, Lowe SW, Hannon GJ, Hammond SM. A microRNA polycistron as a potential human oncogene. Nature. 2005; 435:828-33.

23. Lu J, Getz G, Miska EA, Alvarez-Saavedra E, Lamb J, Peck D, Sweet-Cordero A, Ebert BL, Mak RH, Ferrando AA, Downing JR, Jacks T, Horvitz HR, Golub TR. MicroRNA expression profiles classify human cancers. Nature. 2005; 435:834-38.

24. Croce CM. Causes and consequences of microRNA dysregulation in cancer. Nat Rev Genet. 2009; 10:704-14. 
25. Mathé EA, Nguyen GH, Bowman ED, Zhao Y, Budhu A, Schetter AJ, Braun R, Reimers M, Kumamoto K, Hughes D, Altorki NK, Casson AG, Liu CG, et al. MicroRNA expression in squamous cell carcinoma and adenocarcinoma of the esophagus: associations with survival. Clin Cancer Res. 2009; 15:6192-200.

26. Alder H, Taccioli C, Chen H, Jiang Y, Smalley KJ, Fadda P, Ozer HG, Huebner K, Farber JL, Croce CM, Fong LY. Dysregulation of miR-31 and miR-21 induced by zinc deficiency promotes esophageal cancer. Carcinogenesis. 2012; 33:1736-44.

27. Taccioli C, Garofalo M, Chen H, Jiang Y, Tagliazucchi GM, Di Leva G, Alder H, Fadda P, Middleton J, Smalley KJ, Selmi T, Naidu S, Farber JL, et al. Repression of Esophageal Neoplasia and Inflammatory Signaling by Anti-miR-31 Delivery In Vivo. J Natl Cancer Inst. 2015; 107:djv220.

28. Fong LY, Taccioli C, Jing R, Smalley KJ, Alder H, Jiang Y, Fadda P, Farber JL, Croce CM. MicroRNA dysregulation and esophageal cancer development depend on the extent of zinc dietary deficiency. Oncotarget. 2016; 7:10723-38. https://doi.org/10.18632/oncotarget.7561

29. Warburg O, Wind F, Negelein E. The Metabolism of Tumors in the Body. J Gen Physiol. 1927; 8:519-30.

30. Warburg O. On the origin of cancer cells. Science. 1956; 123:309-14

31. Kelloff GJ, Hoffman JM, Johnson B, Scher HI, Siegel BA, Cheng EY, Cheson BD, O’Shaughnessy J, Guyton KZ, Mankoff DA, Shankar L, Larson SM, Sigman CC, et al. Progress and promise of FDG-PET imaging for cancer patient management and oncologic drug development. Clin Cancer Res. 2005; 11:2785-808.

32. Pavlova NN, Thompson CB. The Emerging Hallmarks of Cancer Metabolism. Cell Metab. 2016; 23:27-47.

33. Ward PS, Thompson CB. Metabolic reprogramming: a cancer hallmark even warburg did not anticipate. Cancer Cell. 2012; 21:297-308.

34. Rottiers V, Näär AM. MicroRNAs in metabolism and metabolic disorders. Nat Rev Mol Cell Biol. 2012; 13:23950.

35. Esau C, Davis S, Murray SF, Yu XX, Pandey SK, Pear M, Watts L, Booten SL, Graham M, McKay R, Subramaniam A, Propp S, Lollo BA, et al. miR-122 regulation of lipid metabolism revealed by in vivo antisense targeting. Cell Metab. 2006; 3:87-98.

36. Fang R, Xiao T, Fang Z, Sun Y, Li F, Gao Y, Feng Y, Li L, Wang Y, Liu X, Chen H, Liu XY, Ji H. MicroRNA-143 (miR-143) regulates cancer glycolysis via targeting hexokinase 2 gene. J Biol Chem. 2012; 287:23227-35.

37. Peschiaroli A, Giacobbe A, Formosa A, Markert EK, Bongiorno-Borbone L, Levine AJ, Candi E, D'Alessandro A, Zolla L, Finazzi Agrò A, Melino G. miR-143 regulates hexokinase 2 expression in cancer cells. Oncogene. 2013; 32:797-802.
38. Yoshino H, Enokida H, Itesako T, Kojima S, Kinoshita T, Tatarano S, Chiyomaru T, Nakagawa M, Seki N. Tumor-suppressive microRNA-143/145 cluster targets hexokinase-2 in renal cell carcinoma. Cancer Sci. 2013; 104:1567-74.

39. Gregersen LH, Jacobsen A, Frankel LB, Wen J, Krogh A, Lund AH. MicroRNA-143 down-regulates Hexokinase 2 in colon cancer cells. BMC Cancer. 2012; 12:232.

40. Denkert C, Budczies J, Kind T, Weichert W, Tablack P, Sehouli J, Niesporek S, Könsgen D, Dietel M, Fiehn O. Mass spectrometry-based metabolic profiling reveals different metabolite patterns in invasive ovarian carcinomas and ovarian borderline tumors. Cancer Res. 2006; 66:10795-804.

41. Buckendahl AC, Budczies J, Fiehn O, Darb-Esfahani S, Kind T, Noske A, Weichert W, Sehouli J, Braicu E, Dietel M, Denkert C. Prognostic impact of AMP-activated protein kinase expression in ovarian carcinoma: correlation of protein expression and GC/TOF-MS-based metabolomics. Oncol Rep. 2011; 25:1005-12.

42. Wikoff WR, Grapov D, Fahrmann JF, DeFelice B, Rom WN, Pass HI, Kim K, Nguyen U, Taylor SL, Gandara DR, Kelly K, Fiehn O, Miyamoto S. Metabolomic markers of altered nucleotide metabolism in early stage adenocarcinoma. Cancer Prev Res (Phila). 2015; 8:410-18.

43. Fahrmann JF, Grapov DD, Wanichthanarak K, DeFelice BC, Salemi MR, Rom WN, Gandara DR, Phinney BS, Fiehn O, Pass H, Miyamoto S. Integrated Metabolomics and Proteomics Highlight Altered Nicotinamide- and Polyamine Pathways in Lung Adenocarcinoma. Carcinogenesis. 2017. bgw205.

44. Miyamoto S, Taylor SL, Barupal DK, Taguchi A, Wohlgemuth G, Wikoff WR, Yoneda KY, Gandara DR, Hanash SM, Kim K, Fiehn O. Systemic Metabolomic Changes in Blood Samples of Lung Cancer Patients Identified by Gas Chromatography Time-of-Flight Mass Spectrometry. Metabolites. 2015; 5:192-210.

45. Barupal DK, Haldiya PK, Wohlgemuth G, Kind T, Kothari SL, Pinkerton KE, Fiehn O. MetaMapp: mapping and visualizing metabolomic data by integrating information from biochemical pathways and chemical and mass spectral similarity. BMC Bioinformatics. 2012; 13:99.

46. Kotera M, Hirakawa M, Tokimatsu T, Goto S, Kanehisa M. The KEGG databases and tools facilitating omics analysis: latest developments involving human diseases and pharmaceuticals. In: Wang J, Tan A, Tian T (eds). Next Generation Microarray Bioinformatics. Methods in Molecular Biology (Methods and Protocols), vol 802. Humana Press. 2012. pp. 19-39.

47. Bolton EE, Wang Y, Thiessen PA, Bryant SH. PubChem: integrated platform of small molecules and biological activities. Annu Rep Comput Chem. 2008; 4:217-41.

48. Vander Heiden MG, Cantley LC, Thompson CB. Understanding the Warburg effect: the metabolic requirements of cell proliferation. Science. 2009; 324:1029 
33.

49. Pegg AE. Polyamine metabolism and its importance in neoplastic growth and a target for chemotherapy. Cancer Res. 1988; 48:759-74.

50. Gerner EW, Meyskens FL Jr. Polyamines and cancer: old molecules, new understanding. Nat Rev Cancer. 2004; 4:781-92.

51. Wanichthanarak K, Fan S, Grapov D, Barupal DK, Fiehn O. Metabox: A Toolbox for Metabolomic Data Analysis, Interpretation and Integrative Exploration. PLoS One. 2017; 12:e0171046.

52. Mathupala SP, Rempel A, Pedersen PL. Glucose catabolism in cancer cells: identification and characterization of a marked activation response of the type II hexokinase gene to hypoxic conditions. J Biol Chem. 2001; 276:43407-12.

53. Shinohara Y, Yamamoto K, Kogure K, Ichihara J, Terada H. Steady state transcript levels of the type II hexokinase and type 1 glucose transporter in human tumor cell lines. Cancer Lett. 1994; 82:27-32.

54. Mathupala SP, Ko YH, Pedersen PL. Hexokinase II: cancer's double-edged sword acting as both facilitator and gatekeeper of malignancy when bound to mitochondria. Oncogene. 2006; 25:4777-86.

55. Ni Y, Meng L, Wang L, Dong W, Shen H, Wang G, Liu Q, Du J. MicroRNA-143 functions as a tumor suppressor in human esophageal squamous cell carcinoma. Gene. 2013; 517:197-204.

56. Dietrich DR. Toxicological and pathological applications of proliferating cell nuclear antigen (PCNA), a novel endogenous marker for cell proliferation. Crit Rev Toxicol. 1993; 23:77-109.

57. Wang L, Chen J, Chen L, Deng P, Bu Q, Xiang P, Li M, Lu W, Xu Y, Lin H, Wu T, Wang H, Hu J, et al. 1H-NMR based metabonomic profiling of human esophageal cancer tissue. Mol Cancer. 2013; 12:25.

58. Patra KC, Wang Q, Bhaskar PT, Miller L, Wang Z, Wheaton W, Chandel N, Laakso M, Muller WJ, Allen
EL, Jha AK, Smolen GA, Clasquin MF, et al. Hexokinase 2 is required for tumor initiation and maintenance and its systemic deletion is therapeutic in mouse models of cancer. Cancer Cell. 2013; 24:213-28.

59. Tohma T, Okazumi S, Makino H, Cho A, Mochiduki R, Shuto K, Kudo H, Matsubara K, Gunji H, Ochiai T. Relationship between glucose transporter, hexokinase and FDG-PET in esophageal cancer. Hepatogastroenterology. 2005; 52:486-90.

60. Fukunaga T, Okazumi S, Koide Y, Isono K, Imazeki K. Evaluation of esophageal cancers using fluorine-18fluorodeoxyglucose PET. J Nucl Med. 1998; 39:1002-07.

61. Tomasetti M, Amati M, Santarelli L, Neuzil J. MicroRNA in Metabolic Re-Programming and Their Role in Tumorigenesis. Int J Mol Sci. 2016; 17:17.

62. Jiang S, Zhang LF, Zhang HW, Hu S, Lu MH, Liang S, Li B, Li Y, Li D, Wang ED, Liu MF. A novel miR-155/miR143 cascade controls glycolysis by regulating hexokinase 2 in breast cancer cells. EMBO J. 2012; 31:1985-98.

63. Zhou P, Chen WG, Li XW. MicroRNA-143 acts as a tumor suppressor by targeting hexokinase 2 in human prostate cancer. Am J Cancer Res. 2015; 5:2056-63.

64. Wan SG, Taccioli C, Jiang Y, Chen H, Smalley KJ, Huang K, Liu XP, Farber JL, Croce CM, Fong LY. Zinc deficiency activates S100A8 inflammation in the absence of COX-2 and promotes murine oral-esophageal tumor progression. Int J Cancer. 2011; 129:331-45.

65. Sumner LW, Amberg A, Barrett D, Beale MH, Beger R, Daykin CA, Fan TW, Fiehn O, Goodacre R, Griffin JL, Hankemeier T, Hardy N, Harnly J, et al. Proposed minimum reporting standards for chemical analysis Chemical Analysis Working Group (CAWG) Metabolomics Standards Initiative (MSI). Metabolomics. 2007; 3:211-21.

66. Cao Y, Charisi A, Cheng LC, Jiang T, Girke T. ChemmineR: a compound mining framework for $\mathrm{R}$. Bioinformatics. 2008; 24:1733-34. 